\title{
PLASTIC DEFORMATION INFLUENCE ON INTRINSIC MAGNETIC FIELD OF AUSTENITIC BIOMATERIALS
}

\author{
Milan Smetana* — Klára Čápová * Vladimír Chudáčik ${ }^{*}$ \\ Peter Palček ${ }^{* *}$ — Monika Oravcová ${ }^{* *}$
}

\begin{abstract}
This article deals with non-destructive evaluation of austenitic stainless steels, which are used as the biomaterials in medical practice. Intrinsic magnetic field is investigated using the fluxgate sensor, after the applied plastic deformation. The three austenitic steel types are studied under the same conditions, while several values of the deformation are applied, respectively. The obtained results are presented and discussed in the paper.
\end{abstract}

K e y w o r d s: non-destructive evaluation, austenitic stainless steel, biomaterial, fluxgate sensor

\section{INTRODUCTION}

A role of non-destructive evaluation (NDE) of material structures is undeniable worldwide. Periodic inspection of components and devices ensures their safe, effective and long-term operation. New methods and devices are still being developed and designed to tackle gradually increasing demands for reliable detection and precise characterization of material discontinuities. NDE techniques are widely used in a range of industries for the inspection of various complex structures. Increased R\&D activities in the field of NDE have been motivated by the need for precise evaluation of materials, cracks and flaws, for the assessment of the expected life of mechanical components $[1,2]$. New technologies from the last decades have allowed to design and to develop such type of sensors that have properties suitable for the electromagnetic NDE applications (eNDE). In the present, biomedical engineering has also become a very important field of eNDE interest. A number of implantable conductive materials (here referred to as biomaterials) have increased in recent last decades. These components are in direct contact with living organism. Moreover, they are surrounded by very aggressive environment, under the cyclic loading. This fusion may lead to changes of their mechanic and electromagnetic properties. These changes are measurable using appropriate sensors and thus, the information about their state may be introduced.

This article deals with non-destructive evaluation of the austenitic stainless steels, in terms of intrinsic magnetic field mapping, after the plastic deformation. Three different steel types are evaluated. The main aim of this work is to reveal the relationship between applied plastic deformation and changes in magnetic properties of the material. These results may lead to quantification of the induced martensitic component, which is in direct correlation with changes of mechanical properties. The experimental material is evaluated "in vitro".

\section{AUSTENITIC STEELS AS BIOMATERIALS: THEORETICAL BACKGROUND}

Biomaterials as a non-living media are used in medical environment, to interact with living system. These materials are directly in contact with the biological systems. They are often used or adapted for a medical application, and thus comprise whole or part of a living structure or biomedical device which performs, augments, or replaces a natural function. One of the primary reasons that biomaterials are used, is to physically replace hard or soft tissues, which have become damaged or destroyed through some pathological processes. One of the most prominent application areas for biomaterial is for orthopedic implant devices [3,4]. In addition to orthopedics, metallic implants are used in maxillofacial surgery, cardiovascular surgery, and as dental materials. Although many metals and alloys are used for medical device applications, the most commonly employed are austenitic stainless steels, commercially pure titanium and titanium alloys, and cobalt-base alloys [5-[7].

Austenitic stainless steels based on $\mathrm{Fe}-\mathrm{Cr}-\mathrm{Ni}$ are characterized as high corrosion resistance materials with high bio-tolerance, low thermal conductivity and relatively high strength. They are ranked among paramagnetic materials due to their austenitic structure. Austenitic steels are deformed by slipping and also by twinning, during the plastic deformation. Deformation martensite structure may occur by the twinning deformation, which has the ferromagnetic properties. The corrosion resistance depends on high content of $\mathrm{Cr}$. The austenitic structure is

Faculty of Electrical Engineering, University of Žilina, Univerzitná 1, 01026 Žilina, Slovakia, ${ }^{*}$ Department of Electromagnetic and Biomedical Engineering, milan.smetana@fel.uniza.sk, klara.capova@fel.uniza.sk, vladimir.chudacik@fel.uniza.sk, ${ }^{* *}$ Department of Material Engineering, peter.palcek@fstroj.uniza.sk, monika.oravcova@fstroj.uniza.sk 
Table 1. Spectral analysis of the experimental material chemical composition

\begin{tabular}{cccccccccc}
\hline Material & $\mathrm{C}$ & $\mathrm{Si}$ & $\mathrm{Mn}$ & $\mathrm{Cr}$ & $\mathrm{Mo}$ & $\mathrm{Ni}$ & $\mathrm{N}$ & $\mathrm{Ti}$ & $\mathrm{Fe}$ \\
\hline AISI 304 & 0.0509 & 0.401 & 1.33 & 19.88 & 0.235 & 8.19 & 0.15 & 0.0048 & rest \\
AISI 316L & 0.0457 & 0.557 & 1.40 & 17.92 & 2.26 & 10.32 & 0.04 & 0.0095 & rest \\
AISI 316Ti & 0.0537 & 0.716 & 1.39 & 17.70 & 2.28 & 11.11 & 0.02 & 0.145 & rest \\
\hline
\end{tabular}

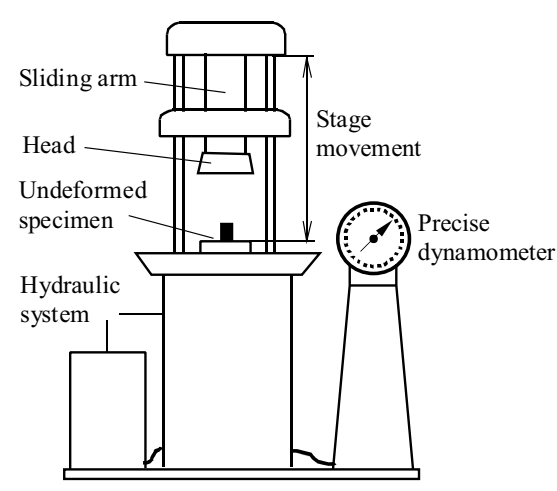

Fig. 1. Universal ripper ZDM30 for plastic deformation realization

given by containing at least $8 \%$ content of $\mathrm{Ni}$. Corrosion resistance is determined by the ability to create a passive Cr oxide-layer on the surface of the material. The addition of $2-2.5 \%$ of Mo increases the rate of formation of passive oxide layer and it improves the corrosion resistance. Furthermore, these alloys may be stabilized by Ti addition, which bonds with carbon and it prevents the chromium carbides segregation at the grain boundaries, $[10,11]$

\section{EXPERIMENTAL SET-UP}

The used experimental biomaterial - austenitic stainless steel specimens are inspected in this study. Two different biomaterial types, according to the AISI (The American Iron and Steel Institute) standard, are evaluated: 316L (low carbon content) and 316 Ti (stabilized with $\mathrm{Ti}$ ) types. These materials are used for biomedical applications. In addition, the AISI 304 is also inspected. This material has a high $\mathrm{Cr}$ content, but do not contain Mo and Ti. It may contain a small amount of ferrite component. Initially, the AISI 304 material is not primarily used for realization of implants, in biomedical praxis. The reason: this steel is now considered unsuitable for surgical implants due to its poor track record, particularly in the aspect of pitting corrosion $[8,9]$. The chemical composition of the inspected materials is listed in the Tab. 1.

Initially, all the inspected specimens are prepared from one piece of material, by the cutting at the defined dimensions. Thus, all the specimens have the cylindrical shape, with an initial height (measured from the base to the top) of $h=14 \mathrm{~mm}$ and with radius of $r=6 \mathrm{~mm}$. It is very important to be all the specimens dissolutionally annealed after the mechanical cutting. The samples underwent the recrystallization annealing process at the temperature of
$T=850{ }^{\circ} \mathrm{C}$ for time of $t=15 \mathrm{~min}$, followed by air cooling to reduce the strength applied during cold-working. Thus, the intrinsic magnetic field caused by the cutting, is eliminated. This regime is defined as the reference state. Then the process of the controlled plastic deformation may be applied. The deformation is performed by mechanical pressing of the opposite sides of the cylindrical specimens, using the ripper system of ZDM30, Fig. 1.

Four different values of the applied plastic deformation are realized: $P_{D 1}=5 \%, P_{D 2}=10 \%, P_{D 3}=20 \%$ and $P_{D 4}=40 \%$. This percentage values represent shortening of the specimen after the applied deformation, in comparison with the reference (non-deformed) specimen, which has the length of $P_{\mathrm{REF}}=100 \%$, Fig. 2. The fluxgate magnetometer, shown in Fig. 3, is used as the sensing element for measuring of the intrinsic magnetic field. This sensor picked-up the response signal in the sensitive axis, while its voltage output signal may be converted to the magnetic field intensity, using the calibration curve of the sensor.

Used type is the commercial one, made by Canon Inc. The sensor is positioned normally to surface of the inspected specimen, while its sensitive axis is oriented in parallel with the axis of each specimen. The sensor allows to measure magnetic field in the frequency range to $3.4 \mathrm{kHz}$.

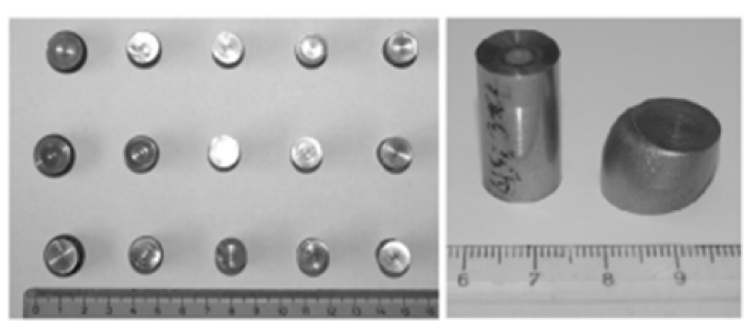

Fig. 2. Inspected steel specimens (left); specimens before/after plastic deformation (right)

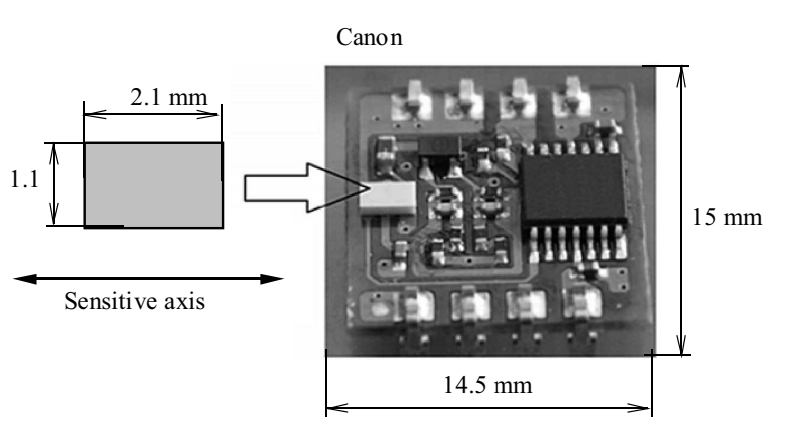

Fig. 3. The sensing element 


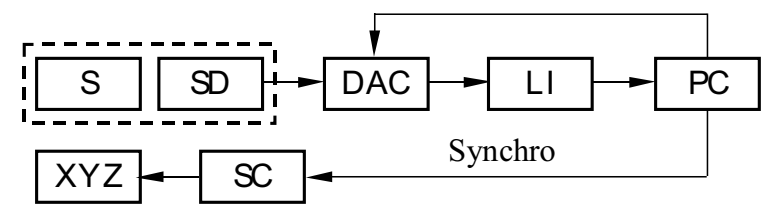

Fig. 4. Block diagram of the experimental set-up: $\mathrm{S}-$ specimen under inspection, SD - sensing device (fluxgatye sensor), DAC data acquistion card, XYZ - 3-axis linear stagde, LI - lock-in amplifier, SC — stage controller, PC — personal computer

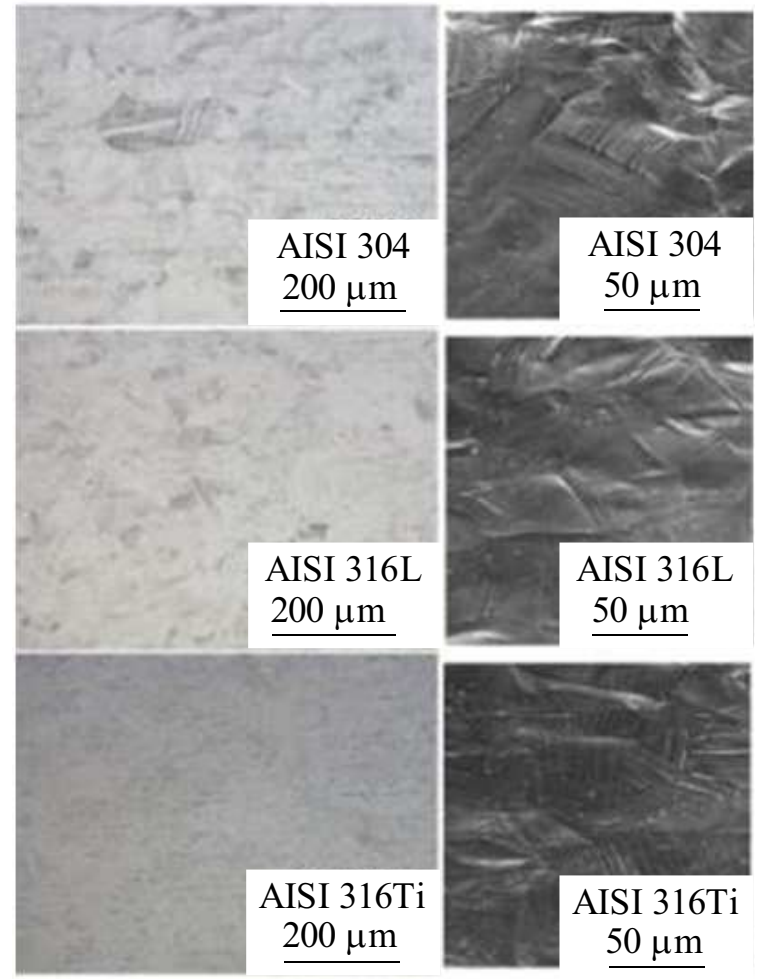

Fig. 5. Structure of the austenitic stainless steels at initial state (left) and surface of the inspected material after plastic deformation (right)

Thus, the magnetic field values are sensed, for the creation of the resulting graphs. The output signal of the sensor (the stationary component is measured) is filtered using the lock-in amplifier (Signal Recovery 7280) and acquired using the DAQ system, Fig. 4.

Each specimen is inspected as follows: a usual raster two-dimensional scan is performed over the specimen. Thus, the inspected area has a square shape, with dimensions of dims $=30 \mathrm{~mm} \times 30 \mathrm{~mm}$, while the resolution between individual scanning lines is set to res $=0.3 \mathrm{~mm}$. It gives in results of $n=100$ scanning lines per each specimen. Further, the sensor is positioned in constant distance from the top side of each specimen, at the so-called lift-off distance of $l_{0}=2 \mathrm{~mm}$. The gained signals are acquired with the resolution of $r_{\mathrm{DAQ}}=16 \mathrm{bits} / \mathrm{channel}$ and with sampling frequency of $f_{\mathrm{s}}=2 \mathrm{kS} / \mathrm{sec}$. User interface for data manipulation, controlling the stage and processing the data are created and designed using the LabVIEW (virtual instrumentation).

\section{RESULTS AND DISCUSSION}

The obtained results of the experimental measurements are given in this section. Figure 5 shows microscopy images of the inspected material, before and after plastic deformation. The steels have the initial state as follows: the single-phase austenitic structure with a minimal content of $\delta$-ferrite. Besides the austenite, also sulfides, phosphates and carbides inclusions may be observed at the images. Carbides are on the base of Fe-Cr-C (AISI 304 and AISI 316L) and on the base of Fe-Ti-C in the case of AISI 316Ti. Furthermore, the annealed twins, as the result of previous heat treatment, are identified in the structure. Further, Fig. 5 displays the surface of the inspected stainless steels, after the plastic deformation. This one was identified at all the inspected specimens. It was caused by the slipping and twinning. The twinning mechanism has approximately the same portion as the deformation by slipping. The rate of martensite deformation is proportional to the applied plastic deformation and subsequently to changes in the magnetic properties of the investigated material.
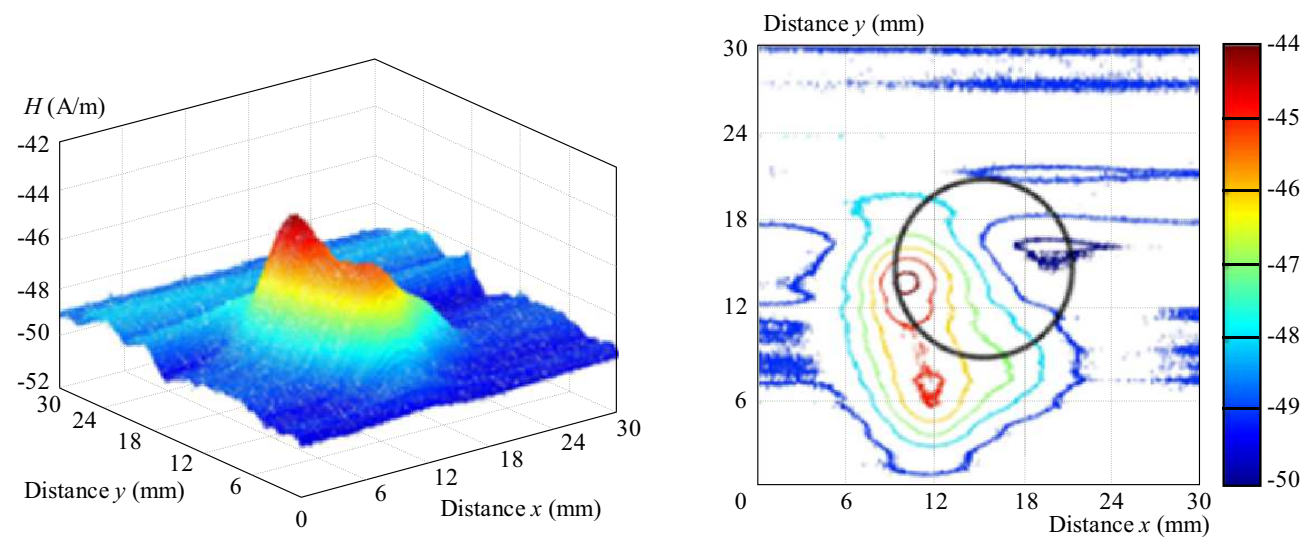

Fig. 6. Experimental results: intrinsic magnetic field, AISI 304, $P_{D 2}=10 \%$ 

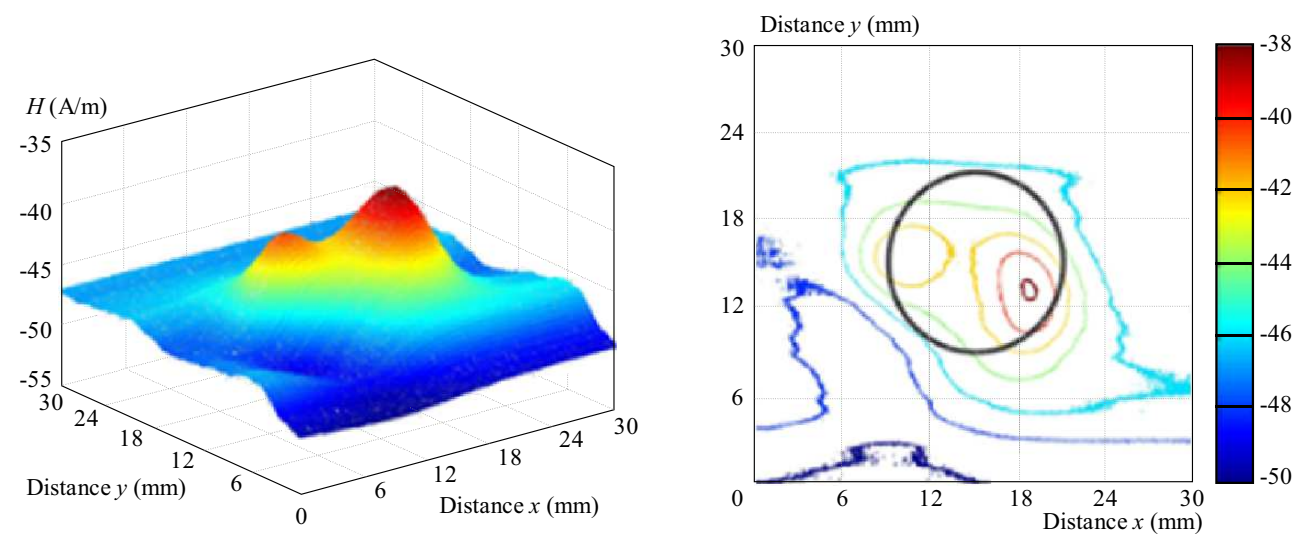

Fig. 7. Experimental results: intrinsic magnetic field, AISI 304, $P_{D 3}=20 \%$
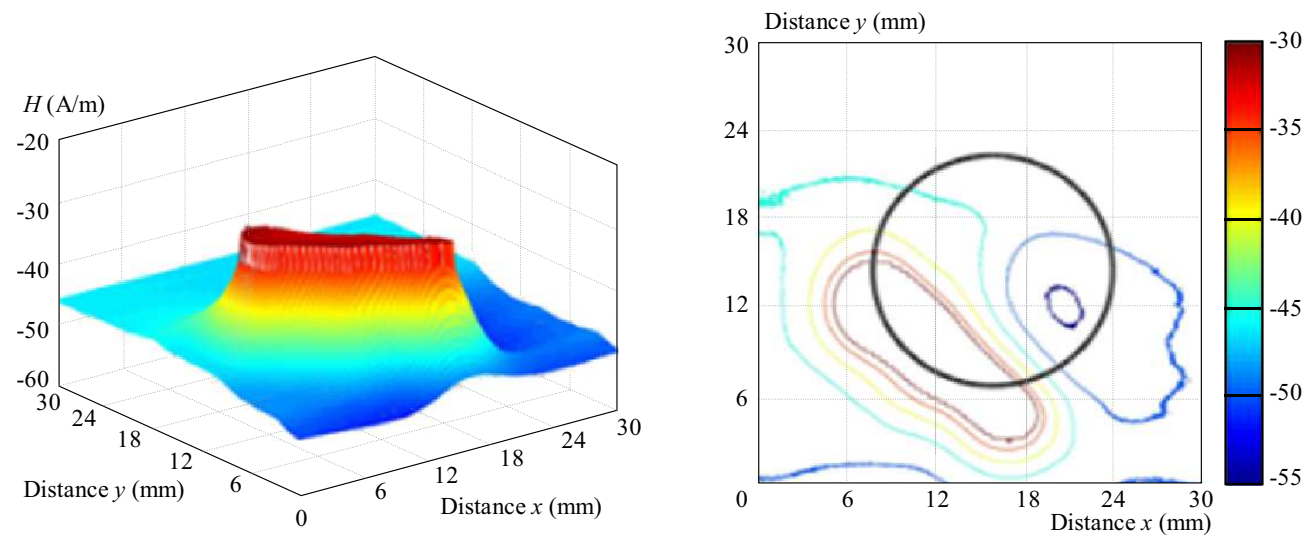

Fig. 8. Experimental results: intrinsic magnetic field, AISI 304, $P_{D 4}=40 \%$
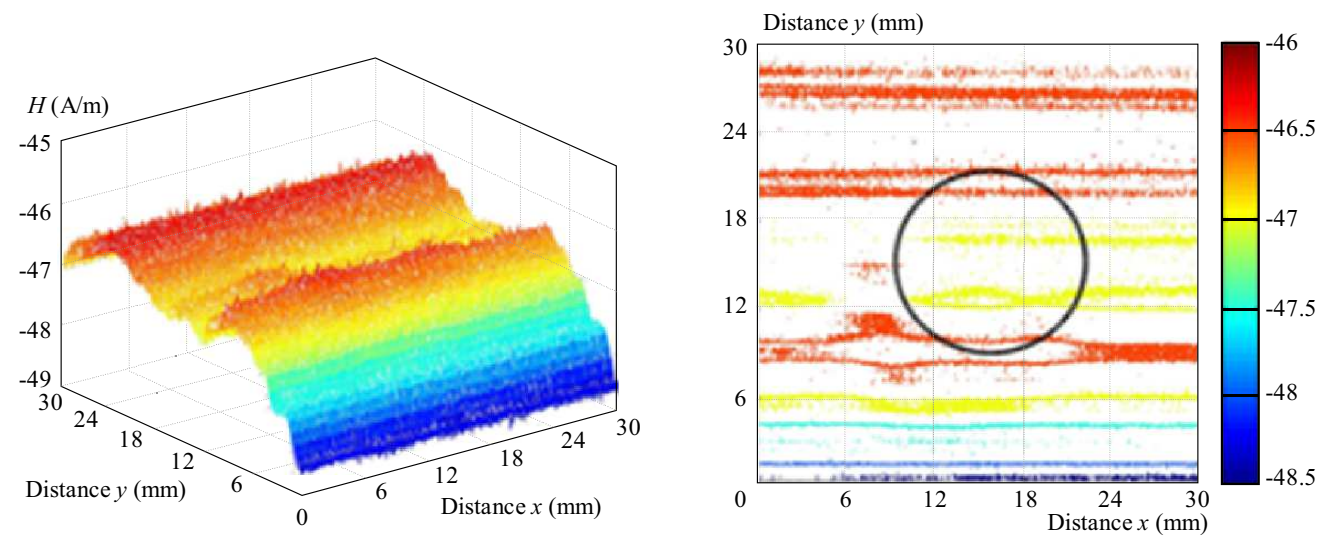

Fig. 9. Experimental results: intrinsic magnetic field, AISI 316L, $P_{D 3}=20 \%$

Next section presents the two different types for displaying of the results: the three-dimensional magnetic field mapping and the surface waveforms, with shown material contours. All the figures display the intrinsic magnetic field $H$, and its distribution over the surface of inspected specimens. Because of directional properties of the fluxgate sensor, the field values reach also negative values.
In total, there are fifteen measurements for the all specimens, to be the intrinsic magnetic field mapped and displayed. All of the results are not processed as the differential responses. It means that the background (surrounding noise) signal is taken into account. Its influence is not eliminated (by subtracting from the individual measurements) in the resulting waveforms. Thus, the real measurement conditions are respected. The normal component of the intrinsic magnetic field is evaluated. It 

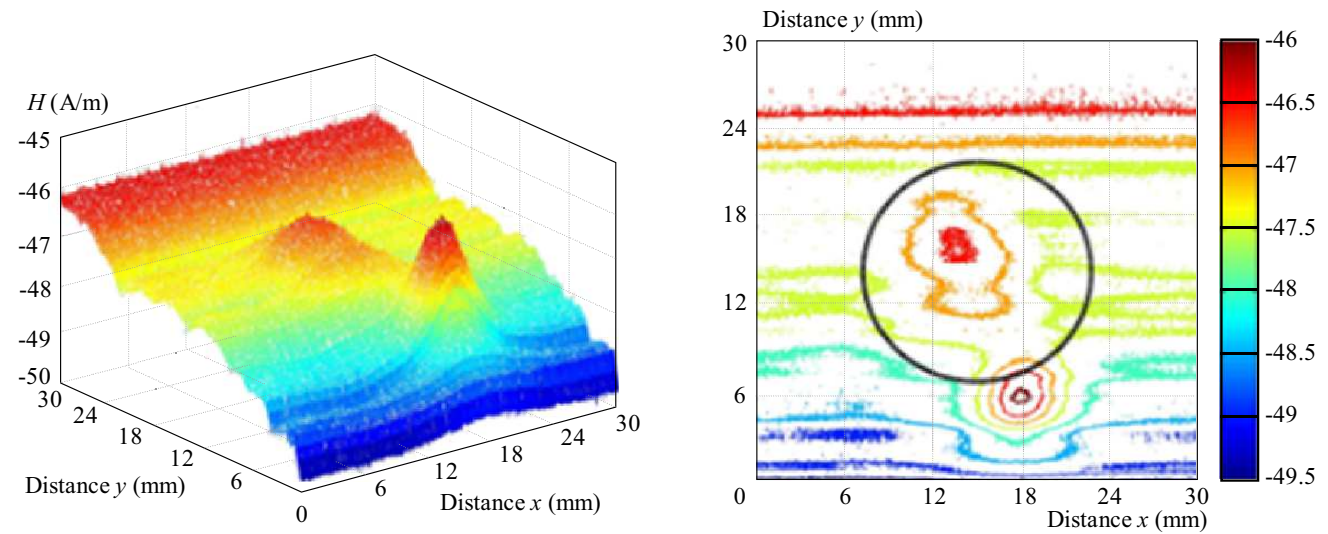

Fig. 10. Experimental results: intrinsic magnetic field, AISI 316L, $P_{D 3}=40 \%$
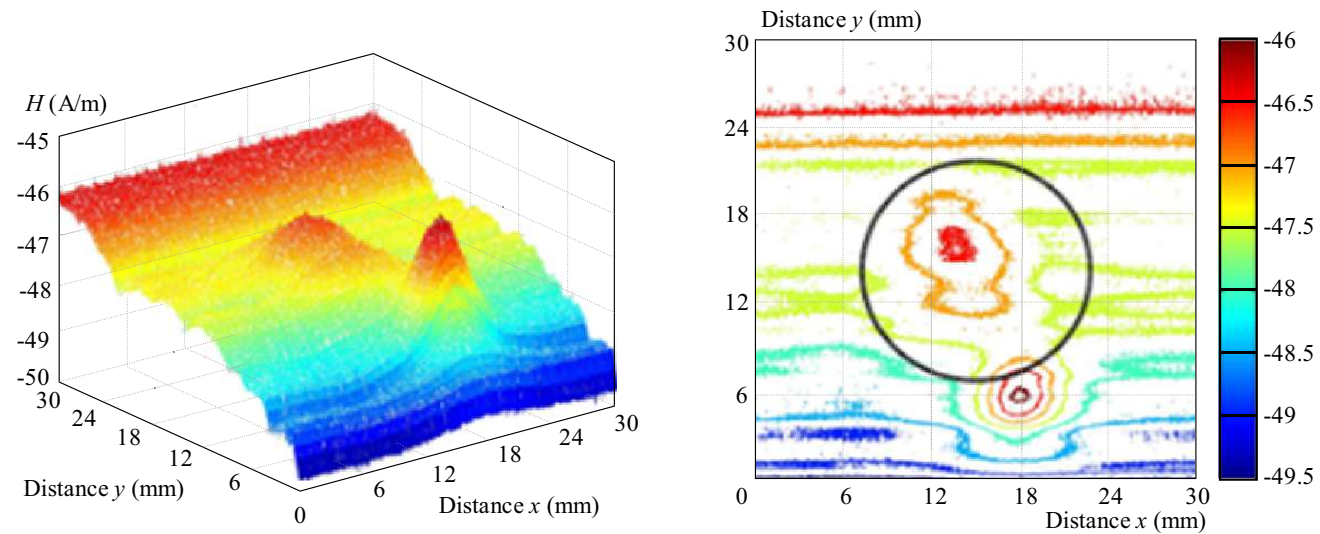

Fig. 11. Experimental results: intrinsic magnetic field, AISI 316Ti, $P_{D 3}=20 \%$
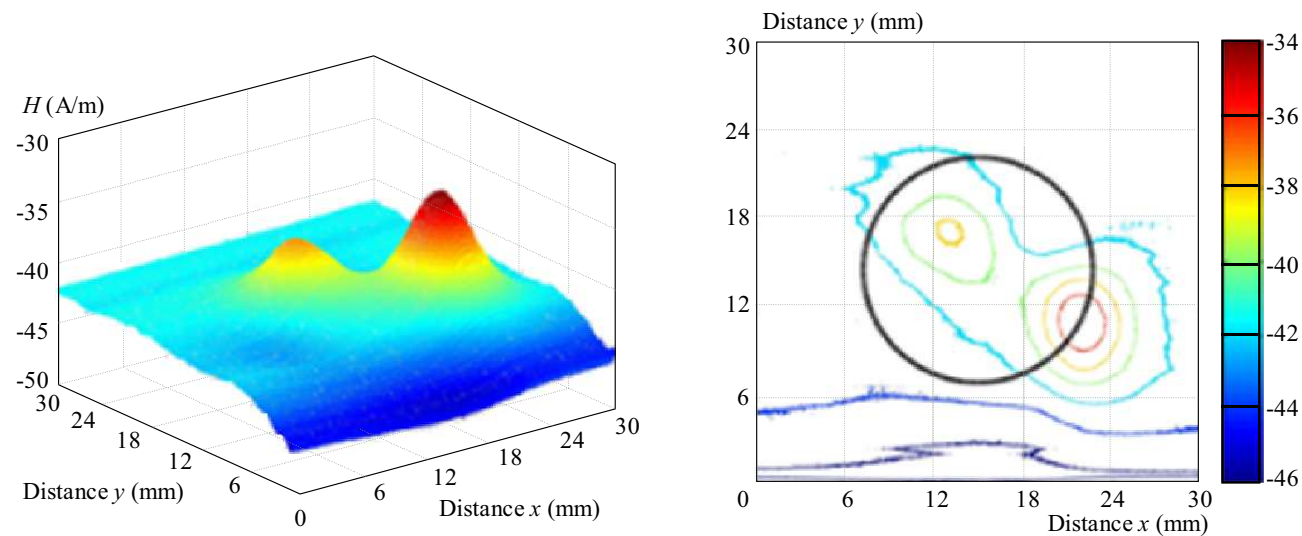

Fig. 12. Experimental results: intrinsic magnetic field, AISI 316Ti, $P_{D 4}=40 \%$

means that the fluxgate sensor is positioned normally to the surface of inspected material, during the inspection.

Figures 6 to 8 show gained results obtained during the AISI 304 material inspection. It can be observed that applied plastic deformation rate has the significant influence on the resulting magnetic field of the specimens. Accordingly, the measurable changes of the magnetic field are feasible from $P_{D}=10 \%$ of the applied plastic deformation. Moreover, the highest rate of the deformation gives a very strong magnetic field signal, by which the sensor is completely saturated, Fig. 8. Based on this fact, it is possible to perform the measurements also at higher lift-off distance.

This is in correlation with the main philosophy of the measurements: the main requirement is to detect the intrinsic magnetic field from the surface of the human body. 
In such case, the lift-off distance may reach up to several centimeters.

Figures 9 and 10 show individual waveforms obtained by inspection of the AISI 316L. In comparison with the 304 one, it can be clearly seen that this type of the austenitic steel involves weaker magnetic field.

On the other hand, the changes are detectable from the value of $P_{D}=20 \%$ of the applied deformation. The strongest signal is obtained for the highest plastic deformation rate, Fig. 10. In comparison with the previous results, it can be stated that the AISI 316 steel has a weaker signal, for the same rate of the plastic deformation. Figures 11 and 12 show the magnetic field of the specimens, obtained for the AISI 316Ti, respectively. As can be seen, the results are quite comparable with the AISI 316L one.

The both cases show quite weaker signal, in comparison with the AISI 304 material. However, also these field values are detectable, even though higher values of the plastic deformation were applied.

The all obtained results may be concluded: all the inspected materials reveal strongly non-homogeneous intrinsic magnetic field, measurable by the fluxgate sensor in given lift-off distance. Further, the higher the plastic deformation rate, the strongest the resulting material magnetic field signal.

\section{CONCLUSION}

The article presented non-destructive evaluation of austenitic stainless steel materials, by measuring of the intrinsic magnetic field after the plastic deformation. Three different steel types were inspected under the same conditions, while the magnetic field was mapped using the commercial fluxgate sensor. As can be seen from the gained results, all the inspected stainless steel types reveal their intrinsic magnetic field. It can be concluded: the higher plastic deformation rate, the stronger the intrinsic magnetic field. Further, the strongest signals were detected for the AISI 304. This lies in fact, that this material has the highest level of induced deformation martensitic component. The results obtained for both the AISI $316 \mathrm{~L}$ and AISI 316 Ti materials, possesses approximately the same information content. Their intrinsic magnetic field was detectable from the value of $P_{D}=20 \%$, by used fluxgate sensor.

The biomaterials AISI $316 \mathrm{~L}$ and $316 \mathrm{Ti}$, which contain molybdenum, should not become magnetic during cold working. This lies in fact that the stabilized austenitic structure should be resistant to strain induced martensite at the room temperature. On the other hand, the AISI 304 stainless steel contains only minimum molybdenum $(0.235 \%)$ so the strain induced martensite can be easily formed during the cold working. This induced structure is ferromagnetic and also presence of the secondary phases such $\delta$-ferrite may increase the magnetic permeability. This martensitic phase transformation is a result of the plastic deformation. It can be concluded that microstructure and composition of the steels influenced the magnetic permeability of the austenitic stainless steels. The material in this state is not desirable because the patient with implanted replacement may be subjected to magnetic resonance imaging procedure. So the material should be paramagnetic to avoid implant movement or heating during the MRI inspection.

Based on the results, it can be concluded: non-contact method for detection of the intrinsic biomaterial's magnetic field was clearly presented. The obtained results show the strong influence of deformation on the magnetic fields of the austenitic biomaterials and also on the mechanical properties of such implants.

The future work of the authors will address the quantification of the induced martensitic component of the stainless steels used as biomaterials.

\section{REFERENCES}

[1] SMETANA, M.-CAPOVA, K.-PALCEK, P.-ORAVCOVA, M.: Identification of Biomaterial Fatigue Cracks by ECT Method, in Proceedings of the 20th International workshop on Electromagnetic non-destructive evaluation, September 2015, Sendai, Japan.

[2] SMETANA, M.-CAPOVA, K.-PALCEK, P.: Austenitic Steel Magnetic Properties Evaluation after Mechanical Deformation, In: Electromagnetic nondestructive evaluation (XVIII) - Amsterdam: IOS Press BV, 2015, pp. 35-42, Studies in applied electromagnetics and mechanics, vol. 40.

[3] CHEN, Q.-THOUAS, G. A.: Metallic Implant Biomaterials, Material Science and Engineering R (2015), 1-57, Australia.

[4] NIINOMI, M. : Metals for Biomedical Devices, CRC Press, 2010.

[5] McGUIRE, M. F.: Stainless Steels for Design Engineers, ASM International, 2008.

[6] PARK, J. B.-BROZINO, J. D. : Biomaterials - Principles and Applications, CRC Press, 2003.

[7] ORAVCOVA, M.-PALCEK, P.-ZATKALIKOVA, V.CHALUPOVA, M.: The effect of Heat Treatment on Structure Stability of AISI 316Ti, TRANSCOM 2015, University of Zilina, 2015, pp. 224-228.

[8] SKOCOVSKY, P.-BOKUVKA, O.-PALCEK, P.: Material Science, EDIS, 1996.

[9] DOUGLASE. A.: Health Monitoring of Structural Materials and Components, Wiley, 2007.

10] SUMITA, M.-TEOH, S. H.: Durability of Metallic Implant Materials, in Engineering materials for biomedical applications, 2004, pp. 2.1-2.29.

[11] BLACKWOOD, D. J.-SEAH, K. H. W-TEOH, S. H. : Corrosion of Metallic Implants, in Engineering materials for biomedical applications, 2004, pp. 3.1-3.50.

Received 30 March 2016

Milan Smetana (doc, Ing, PhD) was born in Poprad, in 1983. He graduated (master study) at the Department of Electromagnetic and Biomedical Engineering, Faculty of Electrical Engineering, University of Žilina in 2006. He continued with PhD study at the same department in the field of theory of electrical engineering, graduated in 2009. He became an associate professor in the field of theory of electrical engineering in 2014. Currently, he works at the same department. His research activities are focused mainly on non-destructive evaluation of conductive biomaterials, especially using electromagnetic methods. 
Klára Čápová (prof, Ing, PhD) received her MSc degree from the Faculty of Electrical Engineering, Czech Technical University in Prague in 1971 and PhD. degree from the Faculty of Electrical Engineering and Information Technology, Slovak Technical University in Bratislava in 1981. Since 2001 she has been the professor and also the head of the Department of Electromagnetic Engineering and in 2005 up to now at the Department of Electromagnetic and Biomedical Engineering, Faculty of Electrical Engineering, University of Žilina. The main area of her research and teaching activities has moved from the electrical circuits and electromagnetic field theory and its application, mainly the electromagnetic methods for non-destructive evaluation, to their biomedical engineering application connected especially with the biomaterials properties investigation.

Vladimír Chudáčik (Ing) was born in Galanta. He graduated his master study in field of Biomedical Engineering at the Department of Electromagnetic and Biomedical Engineering, Faculty of Electrical Engineering, University of Žilina in 2014. He is nowadays a PhD student at the same department in the field of Theory of Electrical Engineering. His research activities are focused on electromagnetic methods of non-destructive evaluation and on implementation of virtual instrumentation in this field.
Peter Palček (prof, Ing, PhD) was born in 1950. He currently works at the Faculty of Mechanical Engineering, University of Žilina at the Department of Materials Engineering. He received his master degree in 1974 at the University of Transport in Žilina and finished his $\mathrm{PhD}$ degree in physical metallurgy and ultimate limit state of materials at the University of Transport in Žilina in 1980. He was appointed as associate professor at the Division of Physical Metallurgy and Ultimate Limit State of Materials in 1987 and in 1997 he was appointed as a professor for the Division of Materials Engineering. His professional activities are focused on the study of materials properties on the dependence of their structures, focusing on biomaterials and light metal alloys. Besides this, he is specialist in the study of changes in internal damping of metallic materials depending on temperature and loading amplitude.

Monika Oravcová (Ing) was born in Rožňava in 1989. She graduated at the University of Žilina, Faculty of Electrical Engineering at the Department of Electromagnetic and Biomedical Engineering in 2014. She is presently a PhD student at the Department of Materials Engineering, Faculty of Mechanical Engineering, University of Žlina. Her PhD thesis is focused on biomaterials made from austenitic stainless steel that can be used as total hip replacements. 